\title{
STUDENTS' ATTITUDES TOWARDS SCIENCE: WHERE DO WE GO FROM HERE
}

\author{
Elena Elliniadou, \& Chryssa Sofianopoulou \\ Department of Informatics and Telematics, Harokopio University of Athens (Greece)
}

\begin{abstract}
Students' attitudes towards science have long occupied the interest of the scientific community. The confirmed decline of students' interest in pursuing the study of science, alongside the increasing recognition of scientific knowledge's importance and economic utility, makes the issue even more imperative for any society attempting to raise its standards of scientific literacy. Attitudes towards science have been found to depend on variables like instructional teaching and curriculum. The latest research indicates that childhood experiences serve as a major influence on academic interest. The broad recommendation is to concentrate on improving 10 to 14 -year-olds' experience of science. Despite the recent flurry of media interest and the latest research in the scientific community, the school curriculum in most countries is still teaching obsolete science with scarce reference to current, cutting-edge scientific research. There is an urgent need to introduce the concepts of 20th-century Physics within the curriculum and exciting science programs that will enhance the interactive learning experience among students, as is shown by evaluating reports of OECD and PISA results. While this has led to several changes in the curriculum of secondary schooling in some countries, it is still an imperative case for others and definitely for Greece. There are some individual or institutional projects around the globe that introduce modern science and technology to upper primary students, yet of no nationwide effect. This paper aims to review the latest research on students' attitudes towards science and to present the possible next research steps in amplifying students' interest and engagement in science.
\end{abstract}

Keywords: Attitudes, scientific literacy, education research, STEM.

\section{Introduction}

Science has contributed to our modern understanding of the world through technologies and discoveries, establishing new grounds for modern Physics. Despite the importance of these theories, rarely do these become part of lower high or/and primary schools physics curricula worldwide, mostly due to advanced mathematics required for being taught.

However, there has been a growing interest to bring these theories to younger students and the general public as well as a piece of growing evidence that appropriate teaching can result in measurable learning (Blair, Henriksen, \& Hendry, 2016; Dua, Blair, Kaur, \& Choudhary, 2020; Foppoli et al., 2019; Kaur, Blair, Moschilla, Stannard, \& Zadnik, 2017a; Sheldrake, Mujtaba, \& Reiss, 2017).

Nevertheless, there is a decline in student interest in Science, Technology, Engineering and Mathematics (STEM) subjects which causes alarm in societies dependent on technical skills and scientific literacy (Foppoli et al., 2019). The research on the subject is extensive, and the findings are well known: science is perceived as difficult and not relevant to the lives of most people, interest in science declines over the years of secondary schooling, science is more attractive to boys than girls, and problems are most acute in the physical sciences (Barmby, Kind, \& Jones, 2008; Bennett \& Hogarth, 2009). The falling numbers of students choosing to pursue the study of science, have caught the attention of the science education research and has led to focus on the factors that influence attitudes towards science (Barmby et al., 2008).

\section{Attitudes towards Science}

"Attitudes towards science", are defined as a set of affective behaviors in science education including the manifestation of favorable attitudes towards science and scientists, the acceptance of scientific inquiry as a way of thought, the adoption of 'scientific attitudes', the enjoyment of science 
learning experiences, the development of interests in science and science-related activities, and the development of an interest in pursuing a career in science (Archer et al., 2013; Gardner, 1975). It includes the feelings, the beliefs, the values, the disposition held about science, school science, the impact of science on society and the idea of scientists, that have been found to depend on a great number of variables and is addressed as a complex and multi-faceted construct (Osborne, Simon, \& Collins, 2003).

Students' attitudes towards science are, in other words, the preference, the acceptance, the appreciation and the commitment to science (Hacieminoglu, 2016). And, although the research of these attitudes is long enough with numerous studies throughout the decades, it should be noted that, results cannot transfer from one society to another, neither from one time period to another, as it must be regarded as a characteristic of the context in which it has been conducted. Attitude research is an ongoing issue and students' attitudes towards science should be explored according to the current social, financial, religious and educational situation (Barmby et al., 2008).

And the current situation is somehow ready to accept modern Physics, that is, Quantum Physics and Einsteinian Physics, from an early age, in upper primary school or lower secondary as recent studies seem to claim.

\section{Objectives}

It's been in the discussion for many years that new inventions and discoveries should be taught early in primary schools to make science purposeful, attractive and relevant to students' everyday life (Shabajee \& Postlethwaite, 2000) and that the age of 10-14 is a critical time to establish positive attitudes towards science that could lead to scientific careers (Archer et al., 2013; Blair et al., 2016; Eshach \& Fried, 2005). Research has focused upon late elementary and middle school students, in particular, because student attitudes toward science and interest in science-related careers are created before students enter secondary school (Newell, Zientek, Tharp, Vogt, \& Moreno, 2015; Tai, Liu, Maltese, \& Fan, 2006).

The purpose of this paper is to investigate, through a literature review, whether a newly updated curriculum with modern Physics and STEM subjects, combined with gender and culturally inclusive science teaching strategies and hands-on workshops/activity-based learning, affect students' attitudes towards science in late elementary/primary and middle/secondary school students, age 10-12. The questions that led the review were:

-What is the impact of introducing concepts of 21 st-century Physics and STEM activities to younger students in informal scientific environments?

-How attitudes towards science are affected?

-Could an updated science curriculum earlier at school be the answer to negative attitudes towards science and therefore become one solution to the decline of science-related educational pathways?

Results are presented concerning the country conducted.

\section{Australia}

With the thought that "we're underestimating what primary school students can understand in science" Blair (Blair, 2012) and other educators in Western Australia have been bringing Einsteinian physics concepts to primary schools. Exploring the ideas of space, time, and gravity with 11-12-year-olds resulted in interesting conclusions that the subject was very interesting for the students and that they weren't too young to learn these concepts (Blair et al., 2016).

Some years later, an enrichment program on aspects of Einsteinian Physics on Year 6 students, studied science knowledge and attitudes towards science (Pitts et al., 2014). Students felt interested and engaged in the activities but also, at a good age to learn concepts related to Einstein's physics. These efforts and the gravitational waves research (2017) led to Australia's "Einstein-First" project, which aims to teach the basic concepts of modern physics from an early age, with models and analogies appropriate to young students and change the paradigm of school science teaching (Kaur, Blair, Moschilla, Stannard, \& Zadnik, 2017a; 2017c). Interactive and engaging activities were found to enhance students' enjoyment and understanding of the core concepts, and influence attitudes towards science to improvement.

In the context of the "Einstein-First" project, Foppoli ignited a pilot study introducing Einsteinian concepts from an early age, involving teachers, parents and the public in an attempt to gauge support (Foppoli et al., 2019). Results on students' attitudes and learning at ages 11-16 have shown that the fundamental knowledge has been easily grasped and attitudes have been positively correlated. Choudhary, on the other hand, engaging younger ages in a one-day intervention, argues that not only long 20-lesson programs, as the Einstein-First, has influence on students' knowledge and attitudes but also short ones can be significant in influencing their career choices. Results, added to previous findings, indicate that modern physics is readily accepted by students and showed significant evidence that girls respond more positively compared to boys (Choudhary et al., 2018). 


\section{USA}

Attitudinal changes and related content knowledge were explored in a high-quality, one-semester, science after-school program in the USA (Newell et al., 2015). The study investigated whether an activity-based, discovery-oriented intervention -which was also the case in the above studies- affects students' in-school science achievement and interest in pursuing a STEM-related career path. In addition, it examined if the students' attitudes to science could serve as predictors of gains on content knowledge. The findings revealed a positive relationship between students' attitude and academic achievement, serving as predictors recommending further research especially because informal scientific environments may benefit disadvantaged students.

\section{United Kingdom}

The detection of gravitational waves triggered Boyle, in Scotland, to design a teaching module based around this exciting new branch of astronomy and to use it as an opportunity to bring cutting-edge science into the classroom, whilst allowing students to explore future potential exciting careers in physics, astronomy and engineering by inviting "real" scientists (Boyle, 2019a, 2019c; Choudhary et al., 2018). Intending to inspire students to become scientists, improve scientific literacy and aid the development of STEM skills, a gravitational waves-based STEM club took place $1 \mathrm{~h}$ per week for a year. Presented as the perfect scenario to assess the benefits of introducing Einsteinian physics into the lower secondary stages in UK schools and to monitor its effect on the self-belief within the students, particularly that of the girls (Boyle, 2019c), appeared to increase interest in STEM careers throughout the project and to influence girls' view of Physics addressing stereotypes and the current loss of potential. The project had a transformative effect upon achievement, self-efficacy and attitude towards science, confirming previous findings regarding age and gender (Kaur et al., 2020).

"The Blue Marble", a project conducted by Muller and her team, introduced interdisciplinary, hands-on workshops for primary schools on space technology and the role of the research scientist for students aged 6-11. Scientists and postgraduate students delivered workshops on science, scientists and space exploration, dismantling a scientist's stereotypic image. The project's results demonstrated a significant influence on students' enjoyment of science and on the perception of scientists. The key to its success was integrating real-world science into aspects of the curriculum and the interactive, engaging activities delivered by scientists themselves (Muller et al., 2013).

In terms of introducing modern Physics in younger ages, CERN (Conseil Européen pour la Recherche Nucléaire; European Organization for Nuclear Research) conducted a professional development teacher training course, "Playing with Protons" (Alexopoulos et al., 2019; Nantsou, Kapotis, Tombras, 2021). The course initiated in 2016 with Greek primary school teachers and UK teachers have followed since 2018. The teacher program took place at CERN as a one-week summer school training, introduced Particle Physics with innovative, hands-on, engaging activities with teachers committed to teaching their students Particle Physics, in the creative, interactive way they attended. The evaluation of the project did not directly assess students' attitudes towards science, but secondarily, by exploring the impact on teachers' interest, confidence, creativity and knowledge and subsequently of their students'.

\section{Greece}

"Playing with Protons" first got underway in 2016 as a primary school teacher training course at CERN with 10 Greek teachers. Since then, every summer, (except 2020 due to Covid-19) teachers attend the program with the obligation of implementing aspects of modern Physics in their classes (Alexopoulos et al., 2019; "Playing with Protons: Engaging Teachers to Engage K-6 Students with Science, Technology and Innovation," 2016). Research on a four-year implementation of the class program has indicated that the proposed activities and workshops improve significantly the STEM skill of students to a great extent. Additionally, it confirmed that interactive, hand-based activities at school promote students' interest, affecting positively their attitudes towards science and aspirations for the future (Nantsou, Kapotis, Tombras, 2021).

In 2019 a series of educational courses aimed at elementary and secondary education teachers from the Attica region in Greece, launched on a pilot phase. The "Universe for All" with the participation of internationally renowned organizations, research centers and universities, as Perimeter Inst. Canada, European Gravitational Observatory (EGO), National Observatory of Athens (NOA), ("The Universe for All - Eugenides Foundation," 2019), approached modern Physics current issues, latest scientific discoveries, aiming at inspiring and motivating teachers to implement innovative and participative activities with their classes and with students with limited or zero access to modern science. Students benefit from well-trained teachers and literature has pointed out the importance of the teacher figure and style of teaching in attitudes towards science (Barmby et al., 2008; Gardner, 1975; Osborne et al., 2003). 


\section{Discussion}

In this paper we have explored the impact of implementing modern Physics in younger ages by reference to countries conducting teaching modules, workshops, projects and their effect on attitudes towards science. Including Quantum Physics and Einsteinian Theory in the secondary curriculum is something being viewed happening in many countries already, like the Netherlands, Norway, Germany, Argentina, Australia, South Korea (Alstein, Krijtenburg-lewerissa, \& Joolingen, 2020), underpinning the increasing recognition of the need to modernize school physics (Choudhary et al., 2018). But, the implementation of modern Physics at the early stages of education is something new and innovative. The review of the literature has investigated ways of integrating real-world science into primary school curriculum mostly in an informal extracurricular scientific environment. Results show that early childhood experiences serve as a major influence on academic interest, leading to an increase of interest in science, in attitudes and probably in a positive commitment afterward (Osborne et al., 2003).

Still, the decline of interest in science remains a serious matter of concern, especially when looking at the ranking of some countries in OECD reports and PISA results. Greece in particular, in PISA- 2018, ranked 24th, a low score on the scale of the countries involved (Sofianopoulou, Emvalotis, Karakolidis, \& Pitsia, 2019). Particularly Physics report presents that one in four secondary students intend to pursue a science-related educational career (Sofianopoulou, Emvalotis, Pitsia, \& Karakolidis, 2017).

Referring to the third question of this review, if there is a possibility to reverse the decline in students' STEM involvement and subsequently increase students' awareness and performance in science, what should be done is the introduction of exciting science programs, maximizing the interactive learning experience in the formal curriculum and not as outsiders only. Students are willing to experience hands-on activities, acquire new knowledge and approach life with their sense of creativity, curiosity and persistence (Nantsou, T., Kapotis, E.,Tombras, G., 2021). However, teaching expertise (Nantsou, Frache, Kapotis, Nistazakis, \& Tombras, 2020) and constant professional development in universities and academic institutions are not to be overlooked as they are significant variables influencing students' attitudes towards science. The drastic decline of scientific capital at school and university could in part be due to our failure to challenge young people with modern ideas.

\section{Conclusion}

Where do we go from here? Literature insists on trying on new science curriculum at schools, in younger ages with modern and contemporary content, with interactive teaching strategies and advanced teachers' knowledge. Further research must follow, with emphasis on the relationship between attitudes towards science, curriculum and appropriate activities for each matter. We owe it to our students to teach our best understanding of reality and to give them fun ways and scientific ideas to address today's complicated world.

\section{References}

Alexopoulos, A., Pavlidou, M., \& Cherouvis, S. (2019). "Playing with Protons": A training course for primary school teachers at CERN. Physics Education, 54(1). https://doi.org/10.1088/13616552/aae7a4

Alstein, P., Krijtenburg-lewerissa, K., \& Joolingen, W. R. Van. (2020). Teaching and learning special relativity theory in secondary and lower undergraduate education: A literature review. 1-16.

Archer, L., Osborne, J., DeWitt, J., Dillon, J., Wong, B., \& Willis, B. (2013). Young people's science and career aspirations, age $10-14$. King's College London Department of Education \& Professional Studies, 40.

Barmby, P., Kind, P. M., \& Jones, K. (2008). Examining changing attitudes in secondary school science. International Journal of Science Education, 30(8), 1075-1093. https://doi.org/10.1080/09500690701344966

Bennett, J., \& Hogarth, S. (2009). Would you want to talk to a scientist at a party? high school students' attitudes to school science and to science. International Journal of Science Education, 31(14), 1975-1998. https://doi.org/10.1080/09500690802425581

Blair, D., Henriksen, E. K., \& Hendry, M. (2016). Why don't we teach Einstein's theories in school?

Boyle, J. (2019a). Teaching gravitational waves in the lower secondary school. Part I. A teaching module. Physics Education, 54(2). https://doi.org/10.1088/1361-6552/aaf779

Boyle, J. (2019c). Teaching gravitational waves in the lower secondary school. Part III. Monitoring the effect of a STEM intervention on students' attitude, self-efficacy and achievement. Physics Education, 54(2). https://doi.org/10.1088/1361-6552/aaf771 
Choudhary, R. K., Foppoli, A., Kaur, T., Blair, D. G., Zadnik, M., \& Meagher, R. (2018). Can a short intervention focused on gravitational waves and quantum physics improve students' understanding and attitude? Physics Education, 53(6). https://doi.org/10.1088/1361-6552/aae26a

Dua, Y. S., Blair, D. G., Kaur, T., \& Choudhary, R. K. (2020). Can einstein's theory of general relativity be taught to indonesian high school students? Jurnal Pendidikan IPA Indonesia, 9(1), 50-58. https://doi.org/10.15294/jpii.v9i1.22468

Eshach, H., \& Fried, M. N. (2005). Should science be taught in early childhood? Journal of Science Education and Technology, 14(3), 315-336. https://doi.org/10.1007/s10956-005-7198-9

Foppoli, A., Choudhary, R., Blair, D., Kaur, T., Moschilla, J., \& Zadnik, M. (2019). Public and teacher response to Einsteinian physics in schools. Physics Education, 54(1). https://doi.org/10.1088/13616552/aae4a4

Gardner, P. L. (1975). Attitudes to science: A review. Studies in Science Education, 2(1), 1-41. https://doi.org/10.1080/03057267508559818

Hacieminoglu, E. (2016). Elementary school students' attitude toward science and related variables. International Journal of Environmental and Science Education, 11(2), 35-52. https://doi.org/10.12973/ijese.2016.288a

Kaur, T., Blair, D., Choudhary, R. K., Dua, Y. S., Foppoli, A., Treagust, D., \& Zadnik, M. (2020). Gender response to Einsteinian physics interventions in school. Physics Education, 55(3). https://doi.org/10.1088/1361-6552/ab764d

Kaur, T., Blair, D., Moschilla, J., Stannard, W., \& Zadnik, M. (2017). Teaching Einsteinian physics at schools: Part 1, models and analogies for relativity. Physics Education. https://doi.org/10.1088/1361-6552/aa83e4

Kaur, T., Blair, D., Moschilla, J., Stannard, W., \& Zadnik, M. (2017). Teaching Einsteinian physics at schools: Part 3, review of research outcomes. Physics Education. https://doi.org/10.1088/13616552/aa83dd

Muller, C. L., Roberts, S., Wilson, R. C., Remedios, J. J., Illingworth, S., Graves, R., ... Desai, A. (2013). The Blue Marble: A model for primary school STEM outreach. Physics Education, 48(2), 176-183. https://doi.org/10.1088/0031-9120/48/2/176

Nantsou, T., Kapotis, E., Tombras. G. (2021). A Lab of Hands-on STEM Experiments for Primary Teachers at CERN. IEEE Global Engineering Education Conference, EDUCON, 2021-April, paper accepted

Nantsou, T., Frache, G., Kapotis, E. C., Nistazakis, H. E., \& Tombras, G. S. (2020). Learning-by-doing as an educational method of conducting experiments in electronic physics. IEEE Global Engineering Education Conference, EDUCON, 2020-April, 236-241. https://doi.org/10.1109/ EDUCON45650.2020.9125324

Newell, A. D., Zientek, L. R., Tharp, B. Z., Vogt, G. L., \& Moreno, N. P. (2015). Students’ Attitudes Toward Science as Predictors of Gains on Student Content Knowledge: Benefits of an After-School Program. School Science and Mathematics, 115(5), 216-225. https://doi.org/ $10.1111 / \mathrm{ssm} .12125$

Osborne, J., Simon, S., \& Collins, S. (2003). Attitudes towards science: A review of the literature and its implications. International Journal of Science Education, 25(9), 1049-1079. https://doi.org/10.1080/0950069032000032199

Pitts, M., Venville, G., Blair, D., \& Zadnik, M. (2014). An Exploratory Study to Investigate the Impact of an Enrichment Program on Aspects of Einsteinian Physics on Year 6 Students. Research in Science Education, 44(3), 363-388. https://doi.org/10.1007/s11165-013-9386-6

Playing with Protons: Engaging Teachers to Engage K-6 Students with Science, Technology and Innovation. (2016, August 31). Retrieved March 20, 2021, from The Cylindrical Onion website: https://cylindricalonion.web.cern.ch/blogs/playing-protons-engaging-teachers-engage-k-6students-science-technology-and-innovation

Sheldrake, R., Mujtaba, T., \& Reiss, M. J. (2017). Science teaching and students' attitudes and aspirations: The importance of conveying the applications and relevance of science. International Journal of Educational Research, 85(February), 167-183. https://doi.org/ 10.1016/j.ijer.2017.08.002

Sofianopoulou, C., Emvalotis, A., Karakolidis, A., \& Pitsia, V. (2019). An Analysis of the effects of PISA 2015: Performance of Greek students and the influencing factors. Dianeosis, 1-13.

Sofianopoulou, C., Emvalotis, A., Pitsia, V., \& Karakolidis, A. (2017). PISA 2015: PISA (Programme for International Student Assessment). In IEP. https://doi.org/http://dx.doi.org/ 10.1787/9789264266490-en

Tai, R. H., Liu, C. Q., Maltese, A. V., \& Fan, X. (2006). Planning early for careers in science. Science, 312(5777), 1143-1144. https://doi.org/10.1126/science.1128690

The Universe for All - Eugenides Foundation. (2019). Retrieved March 19, 2021, from https://www.eef.edu.gr/en/news/the-universe-for-all/ 